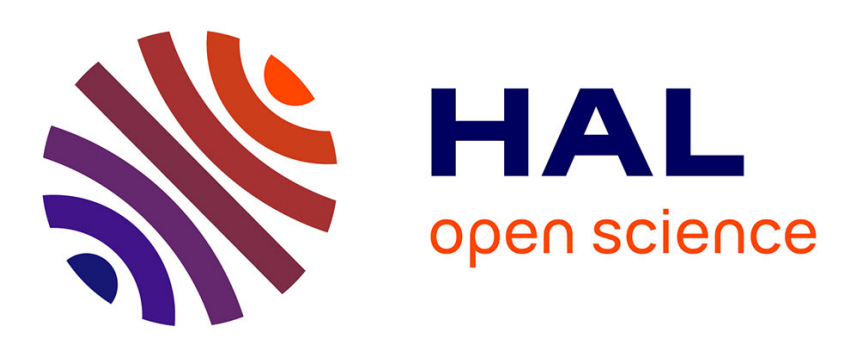

\title{
Assessment of genetic and phenotypic diversity of the giant kelp, Macrocystis pyrifera , to support breeding programs
}

\author{
Carolina Camus, Sylvain Faugeron, Alejandro Buschmann
}

\section{To cite this version:}

Carolina Camus, Sylvain Faugeron, Alejandro Buschmann. Assessment of genetic and phenotypic diversity of the giant kelp, Macrocystis pyrifera, to support breeding programs. Algal Research - Biomass, Biofuels and Bioproducts, 2018, 30, pp.101 - 112. 10.1016/j.algal.2018.01.004 . hal01779411

\section{HAL Id: hal-01779411 \\ https://hal.sorbonne-universite.fr/hal-01779411}

Submitted on 26 Apr 2018

HAL is a multi-disciplinary open access archive for the deposit and dissemination of scientific research documents, whether they are published or not. The documents may come from teaching and research institutions in France or abroad, or from public or private research centers.
L'archive ouverte pluridisciplinaire HAL, est destinée au dépôt et à la diffusion de documents scientifiques de niveau recherche, publiés ou non, émanant des établissements d'enseignement et de recherche français ou étrangers, des laboratoires publics ou privés. 
1 Assessment of genetic and phenotypic diversity of the giant kelp, Macrocystis pyrifera, to

2 support breeding programs.

3

4

5 Carolina Camus a , Sylvain Faugeron ${ }^{\text {b,c }}$, and Alejandro H. Buschmann ${ }^{\text {a,* }}$

6

$7 \quad{ }^{a}$ Centro i mar \& CeBiB, Universidad de Los Lagos, Puerto Montt, Chile.

$8{ }^{\mathrm{b}}$ Centro de Conservación Marina \& CeBiB, Facultad de Ciencias Biológicas, Pontificia

9 Universidad Católica de Chile, Casilla 114-D, Santiago, Chile.

$10{ }^{\mathrm{c}}$ UMI 3614 Evolutionary Biology and Ecology of Algae, CNRS, Sorbonne Universités

11 UPMC Univ. Paris 06, Pontificia Universidad Católica de Chile, Universidad Austral de 12 Chile.

$13 *$ Corresponding author. E-mail address: abuschma@ulagos.cl (A.H. Buschmann)

14

15

16

17

18

19 
21 Abstract

22 The accelerated development of seaweed aquaculture is stimulating research on the genetic

23 drivers of phenotypic diversity of the target species, in order to optimize breeding

24 strategies, to help determine the choice of source populations, and for the selection of traits

25 and varieties that fit with the environmental variability of the production site. This study

26 investigates the spatial variation of the genetic and phenotypic diversities in natural

27 populations of the giant kelp Macrocystis pyrifera, and evaluates the potential for

28 modifying agronomic traits through controlled breeding. Nine microsatellites and 12

29 morphological traits were used to describe the distribution of diversity present along the

30 Southeastern Pacific (SEP) Coast. We expected concordant patterns of spatial

31 discontinuities if the genetic background was driving morphological divergence across

32 habitats. Crossing experiments were made to assess the heritability of specific traits and

33 evaluate the performance of the F1 generation in the laboratory and in open sea cultivation

34 respectively. Our results revealed four genetic clusters along the latitudinal distribution of

35 M. pyrifera populations, tightly correlated with the existence of major environmental

36 discontinuities. These clusters also matched clusters of morphological diversity, suggesting

37 that both morphological and genetic diversities responded to the same environmental

38 drivers. In crossing experiments, no significant differences were detected between selfed

39 and outbred F1, in morphology, growth and chemical components, but a high variability

40 among all different crosses was observed, revealing a high degree of heritable phenotypic

41 variance. Although, the results suggest that the morphological variation of Macrocystis

42 along the SEP coast is strongly driven by the genetic background. Our controlled crosses 
43 were also indicative of a high potential for using this genetic variability in breeding

44 programs for sustainable aquaculture development.

46 Key words: breeding, genetic diversity, phenotypic diversity, microsatellites

49 The use of seaweeds for food/feed, pharmaceutics, textiles, cosmetics, and biofuels [1,2 3

$504,5]$ and the continuously growing demand for raw material, is rapidly changing the way

51 that we humans interact with this natural resource [6]. Encouraged by this increasing

52 demand and the need to reduce the over-exploitation of natural resources, seaweed farming

53 is expanding across several continents from East Asia to Europe, South America and East

54 Africa [7]. Within aquaculture, the global production of seaweeds is 27.3 million tons

$55(27 \%)$, and it has increased by $8 \%$ per year over the past decade [8].

57 programs to increase yield and optimize other relevant agronomic traits $[9,10]$. There is a

58 large amount of information on the development of macroalgal strains in red and brown

59 algae $[11,12,13]$. However, the genetic science behind seaweed breeding and domestication

60 is still in an initial phase, with little conceptual and empirical progress [14]. Several

61 challenges related to the biological peculiarities of algae and their environment are yet to be

62 faced. For instance, the marine environment is more complicated to manipulate than

63 terrestrial environments, where water and nutrient supply, ploughing and other

64 manipulations modify the physico-chemical properties of the soil, and avoid competitors, 
65 predators and most pests and pathogens. Such manipulations are generally not possible in 66 the sea, without significant logistical and infrastructure costs, which are sometimes 67 accompanied by unwanted side effects [15]. Therefore, the increase in productivity must 68 strongly rely on the modification of heritable traits. Yet, the genetic improvement of any 69 agronomic trait must ensure the retention of adequate genetic variance in the targeted traits 70 in order to ensure sufficient scope for adaptation to local environmental variation. Another 71 major difference with land plants, where current breeding efforts are concentrated in 72 already domesticated strains, is the use of wild variants for most seaweed aquaculture 73 initiatives $[16,17]$. Some of the cultivated algal species have never gone through a selective 74 breeding process, based on genetic knowledge. Currently, no more than eight species are in 75 the early stages of domestication [18]. One possible reason for this maybe the ease with 76 which selected strains from wild populations can be cloned in order to establish a new 77 seaweed farm. On the other hand, the complex life histories of algae, add additional 78 conceptual and practical constraints to the implementation of breeding programs [18]. 79 Indeed, trait correlations among life cycle stages may have negative consequences on 80 overall production and/or breeding efforts [19]. For example, selecting for growth rate in 81 the farmed red alga Gracilaria chilensis caused the dominance of heterozygous diploids 82 that lost their capacity for sexual reproduction $[20,21,22]$ and contributed to the critical loss 83 of genetic diversity observed in this species [20]. Strong genetic diversity losses in 84 cultivated populations can have serious consequences for the adaptability of these species 85 and their susceptibility to pests and diseases [6,23,24,25,26,27].

86 One of the main challenges that seaweed-breeding science is currently facing is the 87 lack of general knowledge on the drivers of phenotypic diversity. While a large body of 
88 literature has analysed phenotype responses to environmental variation, relatively little is

89 known about genetic determinism of algal traits and their interactions with environmental determinants. Quantitative genetics approaches on algal models, such as QTL analysis

91 [28,29], have recently emerged, and should provide valuable tools to assist breeding strategies in the near future . However, because most cultivated seaweeds are not yet domesticated, the production of new varieties must rely on an initial genetic pool collected

94 from natural populations. Therefore, a critical initial stage in the establishment of a 95 breeding program is the acquisition of solid knowledge concerning the natural variation in 96 both the phenotypic and genotypic diversities [6]. Several fundamental questions can be 97 tackled from such knowledge: 1) Can selection (either natural or artificial) modify traits of 98 interest such as growth rate or shape (among many other traits)? By investigating signatures 99 of evolutionary divergence between environments within the species range, it is possible to 100 infer the evolvability of the species of interest under natural conditions, which is related to 101 the capacity of different traits to accumulate additive genetic variation. The existence of 102 such genetic diversity is essential to the success of trait improvement by selective breeding. 103 2) Can new varieties be cultivated anywhere or should landraces be established? Because 104 aquaculture systems are deeply influenced by the natural environment, which cannot be 105 easily modified or controlled, it is likely that selected strains or wild progenitors that 106 evolved local adaptations will not be able to grow optimally in non-native environments. In 107 this context, breeding strategies based on selection of local variants should maintain the 108 genetic diversity necessary for optimal growth in the farm environment to secure the 109 sustainability of the production. 3) Should breeding strategy be oriented towards hybrid 110 vigor or "pure" (i.e. inbred) lines? The presence of inbreeding in natural populations may 111 promote inbreeding depression. In this case, hybrid vigor is expected when crossing 
112 different inbred lines. However, if local adaptation has taken place in natural populations, 113 hybrids might break down optimal allelic combinations for specific environments. Also, 114 depending on the level of local genetic diversity, and how representative of this diversity 115 the collection of the initial progenitors was, a breeding program could suffer from high 116 rates of inbreeding and loss of allelic variation if the relationships between the breeding 117 candidates were not considered when making selection decisions. Therefore, efforts to 118 develop diversified germplasms for experimental evaluation of inbreeding effects and local 119 adaptation may complement studies of natural populations, as well as promoting backup 120 conservation strategies [30].

This study aims to investigate the spatial structure of the genetic and phenotypic 122 diversities of the giant kelp, Macrocystis pyrifera (L.) C. Agardh. This species is under a 123 strong and increasing exploitation pressure, mainly for alginate production and as a source 124 of feed for abalone [31]. Regulatory restrictions on kelp exploitation in many countries and 125 the increasing demand for kelp biomass challenges the sustainable exploitation of natural 126 populations, from which the large majority of the biomass is obtained. Biomass production 127 through cultivation is an alternative that is being explored in several countries across its 128 wide distribution range. In Chile, new legislation allows incentives for cultivation and 129 repopulation of seaweeds, providing a positive environment for the installation of a kelp 130 farming industry in the country. Pilot-production has demonstrated that 124 wet ton.ha ${ }^{-1}$ of $131 M$. pyrifera can be achieved using wild individuals to seed ropes for suspended systems 132 [32]. The development of $M$. pyrifera aquafarming is expected to emerge rapidly for 133 several reasons: established procedures for cultivation in hatcheries [33] and open ocean 134 [32] allow for the testing of the agronomic performance of a large array of genotypes and 
135 pilot scale production; technology used to convert biomass to bioethanol implemented at 136 the pilot scale [34,35]; and identification of novel components for food and pharmaceutical 137 uses that add value to the biomass production [5,36,37].

M. pyrifera is considered to be a highly plastic species [38,39], yet some 139 morphological traits were considered to express a strong phylogenetic signal. Indeed, the 140 spatial distribution of different morphotypes based on blade and holdfast shape along the 141 coast was highly correlated with the presence of divergent clades of an ITS2-based 142 phylogeny [40]. Using mitochondrial DNA, Macaya and Zuccarello [41] reported low 143 genetic diversity across the South Eastern Pacific (SEP) but a concordance with the two 144 major biogeographic discontinuities at $33^{\circ} \mathrm{S}$, and $42^{\circ} \mathrm{S}$, suggesting that environmental 145 heterogeneity may be contributing to the distribution of the genetic diversity. Besides the 146 relevance of this information, limited resolution of the molecular markers and the 147 morphological survey restricts our understanding of the spatial patterns of phenotypic 148 variation. The reduced genetic diversity and divergence among habitats or distant regions, 149 and the high phenotypic plasticity were considered as strong arguments for a recent 150 evolutionary history in the southern hemisphere where little or no adaptive divergence has 151 occurred. Consequently, if natural selection had little or no impact on the species 152 phenotypic diversity, it was considered that breeding and strain selection would be 153 insufficient to modify traits and improve productivity under farming conditions. In this 154 study, we challenged this view by developing a comparative study of genetic and 155 morphological divergence across parts of the South American distribution range, with 156 special emphasis on the region of Chiloé where environmental discontinuities are well 157 known. 
We quantified the genetic diversity and its spatial distribution in $M$. pyrifera across the

159 SEP, and its association with morphological diversity. Secondly, we investigated the 160 potential for modifying traits through controlled breeding by testing morphological, growth 161 and chemical differentiation among crosses of $M$. pyrifera with different genetic 162 backgrounds but cultivated in a common garden. Results are discussed in the context of 163 seaweed domestication and sustainable production.

\section{Materials and Methods}

\subsection{Morphological analyses}

167

168

169

177 Component Analysis (PCA) was performed. The level of structuring of the total sample 178 based on morphological traits was assessed by a K-means clustering analysis that performs 179 an iterative alternating fitting process of assigned individuals to a number of specified 
clusters $(\mathrm{K}=2,3$ and 4$)$ in order to maximize the morphological differentiation among groups. Finally, to evaluate the correspondence between morphology and genetic data, a discriminant analysis was performed assigning individuals to groups a priori defined from genetic clustering analyses, and the percentage of correct assignments was estimated as an indicator of the correspondence between morphological and genetic clustering (see below). All multivariate analyses were performed with JMP 10 (North Carolina, USA).

\subsection{Genetic analyses}

A $3 \times 2 \mathrm{~cm}$ piece of blade tissue was excised from each individual for 13 of the 16 collected populations (Dalcahue, Chaulinec and Meulin were not included, Table A1), washed with fresh water and immediately placed into a plastic bag with silica gel crystals for rapid dehydration. Total genomic DNA was isolated from finely ground tissue following [42]. Nine microsatellite loci were selected from [43]: Mp-BC-4N; Mp-BC-13; Mp-BC-25; Mpy-7; Mpy-9; Mpy-11; Mpy-14; Mpy-17 and Mpy-19. PCR reactions were carried out according to [43] with minor modifications in annealing temperatures. PCR products were analyzed on an ABI3130xl Genetic Analyzer (Applied Biosystems, Foster City, California, USA) using 500 LIZ internal standard. Raw allele sizes were scored with GENEMARKER v1.95 and assigned to specific alleles using FLEXIBIN [44].

Descriptive statistics for population genetic diversity, including number of alleles (Nall), observed (Ho) and expected (He) heterozygosities, estimators of inbreeding $\left(\mathrm{F}_{\mathrm{IS}}\right)$ and pairwise population differentiation $\left(\mathrm{F}_{\mathrm{ST}}\right)$ were calculated using GENETIX v 4.05.2 [45].

Isolation by distance was evaluated by a Mantel test with 5000 permutations performed in GENETIX. The identification of genetic clusters was made using the Bayesian clustering 
203 approach implemented in STRUCTURE [46]. The analysis considered possible admixture

204 and correlated allele frequencies among populations as optional settings. The MCMC chain

205 discarded the first 50000 iterations as burn-in, and kept only the subsequent 100000

206 iterations. The analysis was performed 10 times for each of the k-clusters ( $\mathrm{k}=1$ to 12$)$, and

207 all these runs were integrated using STRUCTURE HARVESTER (available at

208 http://taylor0.biology.ucla.edu/structureHarvester/). The uppermost likely number of cluster

209 was defined following Evanno's criteria $\Delta \mathrm{k}[47]$.

210

$211 \quad 2.3$ Germplasm collection and crossing experiment

212 Fertile sporophytes were collected from the sampled sporophytes at the 16 locations (Table

213 A1). The germplasm collection was prepared following [30]. From the collection, three

214 male and three female gametophytes from Puchilco (PUH) and Pargua (PAR) (PAR1,

215 PAR20Q and PUH6Ǫ; PAR10', PAR200' and PUH60 '), were selected for their different

216 genetic background (see Section 3.2.). These gametophytes were transferred from

217 germplasm to new culture conditions to promote vegetative growth, following $[48,49]$.

218 Once sufficient gametophyte biomass was obtained, sexual fertility was induced following

219 [49]. Both inbred and outbred crosses were performed. After 4-6 weeks, juvenile

220 sporophytes were observed. $F_{1}$ sporophyte individuals $(n=30)$ of each cross were weighed,

221 and morphological characters were measured. With the initial and final length and weight,

222 the specific growth rate (SGR) was calculated as $\mathrm{SGR}=\left[\left(\ln \mathrm{x}_{2}-\ln \mathrm{x}_{1}\right) /\left(\mathrm{t}_{2}-\mathrm{t}_{1}\right) * 100\right]$, where

$223 \mathrm{x}_{1}$ and $\mathrm{x}_{2}$ are the measured trait at the beginning $\left(\mathrm{t}_{1}\right)$ and end $\left(\mathrm{t}_{2}\right)$ of the period. 
After 15-20 weeks of cultivation under controlled conditions, between 100-300

225 individuals of each cross were transplanted to a 21-hectare outdoor floating cultivation

226 system in southern Chile (Quenac; see [32]). The sporophytes were attached to ropes, three

227 individuals per meter, at $4 \mathrm{~m}$ depth and monitored for 4-7 months. Each month, three

228 randomly selected individuals of each cross were collected to determine SGR. Also, the

229 number of blades per sporophyte were counted. A fragment of blade tissue of each of these

230 samples was cut, washed and dried in silica gel crystals for genetic analysis. When

231 sporophytes reached maturity, indicated by the presence of sori, the individuals were

232 removed and the reproductive tissue brought to laboratory to collect isolated female and

233 male gametophytes for the germplasm collection. The rest of each of three individuals per

234 cross was completely dried at $60^{\circ} \mathrm{C}$ for $24-48 \mathrm{~h}$, milled and mixed to ensure 235 homogenization for chemical analysis.

\subsection{Chemical characterization}

Carbohydrates (alginate, mannitol and glucans) were determined by first completing a 239 2-step enzymatic depolymerization. The first $24 \mathrm{~h}$ process used cellulases and alginate240 lyase to extract mannitol, convert all glucans to glucose and to solubilize all alginate.

241 Glucans and mannitol were determined via HPLC/IR. The second $24 \mathrm{~h}$ process used an 242 oligoalginate-lyase to break all oligo-alginates into monomers. Ammonia was added in 243 solution which spontaneously converts 4-deoxy-L-erythro-5-hexoseulose urinate (DEHU), 244 an alginate monomer to 5-hydroxypyridine-2-carboxylic acid (5-HPA) which could be detected and quantified on HPLC/UV (for detailed protocols see [35]). 
247 using Folin-Ciocalteu method [51] and Total Phenolic Content (TPC) was determined by

248 the Folin-Ciocalteu method using Gallic acid as standard [52,53,54]. Finally, amino acids

249 were quantified via acid digestion and derivatization followed by HPLC/UV detection $250 \quad[55,56]$.

252 2.5 Statistical analysis of strain selection

253 The growth rates and chemical concentrations of the nine strains were compared with a 1254 way ANOVA after assurance of normality and homoscedasticity. If significant differences 255 were detected, a posteriori Tukey test was performed to identify the source of variation. 256 Growth rates based on the number of blades per individual at the hatchery stage were 257 compared with a Kruskal-Wallis Test. Statistical analysis was performed in JMP 10.0.0.

261 The nine microsatellite loci revealed 287 alleles in 373 genotyped individuals $(5-72$ per 262 locus; Table 1). The average number of alleles per population varied between 5.2 and 13.4 263 in Palqui and Pargua, respectively (Table 1). Heterozygosity for all populations, except 264 Algarrobo, exceeds 0.5 with maximum values of 0.71 in Pargua. There was significant 265 heterozygote deficiency $\left(F_{\text {IS }}<0.01\right)$ in all populations but Los Choros and Puchilco, with 266 significant values ranging from 0.048 in Pucatrihue to 0.250 in Antofagasta (Table 1). 
269 The STRUCTURE analysis indicated the existence of four distinct genetic clusters (Fig. 1):

270 Cluster 1 dominated by the Antofagasta population in northern Chile; cluster 2 comprised

271 Punta Choros and Algarrobo, both in northern-central Chile; cluster 3 included southern

272 Pacific and canal Chacao, from Chome to Pargua (FCO and PAR) populations, and cluster

2734 included populations of the interior sea of Chiloé. Most the individuals had a high

274 probability of belonging to their clusters, however a few (e.g. one to three individuals per

275 cluster) showed an admixture with other clusters (Fig. 1). When assignment of individuals

276 was restricted to only two clusters, the main genetic discontinuity separated northern (i.e.

277 Algarrobo, Punta Choros and Antofagasta) from all southern populations. With three

278 clusters, a new discontinuity appeared separating Chiloé populations of the interior sea

279 from those of the wave exposed coast. Only Pargua, in the Chacao channel (separating

280 Chiloé island from the continent) considered a protected coast site, was assigned to the

281 open coast genetic cluster. Finally, the Antofagasta population appeared as unresolved, with

282 mixed assignments of most its individuals. When defining a fourth cluster, Antofagasta

283 appeared as a highly-differentiated population from all the other populations (Fig. 1). In

284 summary, the analysis illustrated a clear pattern of spatial genetic differentiation within $M$.

285 pyrifera populations along the SEP coast, with strong genetic discontinuities. No signature

286 of isolation by distance was detected (Mantel test: $\left.\mathrm{R}^{2}=0,024 ; p=0,124\right)$.

$288 \quad 3.3$ Morphological variability

289 Three groups were identified in the PCA (Fig. 2). One was composed of individuals 290 belonging to the northern populations only (Antofagasta, Los Choros and Algarrobo). The 
291 second included individuals collected on the exposed coast, south of the first group, and the

292 Chacao channel (Chome, Mehuín, Pucatrihue, Faro Corona, Pargua) and one population

293 from interior sea of Chiloé (Metri). The third group included the remaining individuals

294 from the interior sea of Chiloé (Puchilco, Quenac, Palqui, Dalcahue, Chaulinec, Mehuín 295 and Queilen).

296 The differences between the groups were explained by length, weight, disc diameter and 297 number of blades, all of which had higher values in the interior sea of Chiloé. Sporophytes 298 from the exposed coast had a distribution differentiated mainly by the number of stipes and 299 blade width, with southern individuals having more stipes and thinner blades, closer in 300 character to the pyrifera morphotype than northern individuals which were closer to the 301 integrifolia morphotype.

302 K-means clustering revealed strong differentiation between individuals from the interior sea 303 of Chiloé, and the rest of the southern and northern populations when $\mathrm{K}=2$ (Fig. 3). For K $304=3$, two northern populations (Punta Choros and Algarrobo) were differentiated from the 305 rest of the populations while Quenac (from interior Chiloé) formed a single population306 cluster (Fig. 3). Finally, for $K=4$, the clustering pattern was similar to the genetic 307 clustering (Fig. 1), except that Quenac was still isolated in a different cluster and 308 Antofagasta was not differentiated from the other populations on the exposed shores south 309 of $33^{\circ} \mathrm{S}$. Sporophytes found at Quenac had a particular morphology, with a pronounced 310 conical holdfast, short but significantly wider laminae and longer aerocysts, which was 311 distinct from other individuals of the interior sea.

312 Discriminant analysis of the morphological data using genetic clustering as a priori 313 grouping revealed a high congruence of the spatial distribution of the morphological and 314 genetic variability (Figure 4). The main difference was the population from Metri that was 
assigned to the same group as the northernmost population from Antofagasta. The results were consistent and revealed only $5.0 \%, 12.6 \%$ and $17.4 \%$ of misclassified individuals in $\mathrm{K}=2,3$ and 4, respectively (Table 2). Independent of the level of structure, the correct assignment always exceeded $80 \%$, revealing a strong correspondence between genetic and morphological data.

In a second discriminant analysis (Table 3), individuals were assigned based on environmental groups defined as the three biogeographical units recognized on the SEP coast [57]: Peruvian province $\left(18.4^{\circ}-29^{\circ} \mathrm{S}\right)$, intermediate area $\left(30^{\circ}-41^{\circ} \mathrm{S}\right)$ and Magellan province $\left(42^{\circ}-56^{\circ} \mathrm{S}\right)$. The percentage of correct assignment decreased mainly for the northern genetic cluster (63\%), with $31.5 \%$ and $5.6 \%$ incorrectly assigned to Pacific/Canal Chacao cluster and Chiloé cluster, respectively.

\subsection{Crossing experiments}

One female and one male gametophyte from each of three sporophytes with different genetic backgrounds, were selected from the established germplasm, based on contrasting morphological characteristics of the wild parental sporophytes, all were of the pyrifera morphotype (Table 4). PAR1 and PAR20 belong to the Southern Pacific-Chacao channel genetic cluster, and PUH6 to the Chiloé genetic cluster, all located in the interior sea (e.g. same habitat but different genetic clusters).

Strong and significant differences between crosses were observed in growth rate using weight $(\mathrm{g})$, length $(\mathrm{cm})$ and number of blades per plant. Under hatchery conditions (Fig. 5), Bal 1 and Bal13 had the worst performance, whereas in the open sea culture (Fig. 6) they resumed their growth, and Bal 5 had the lowest growth rates under natural conditions. No 
338 significant differences were observed between the inbred and outbred crosses, neither in

339 hatchery nor in open sea culture. Furthermore, holdfast morphology developed differently

340 between crosses, with some extreme variability, i.e. from a well-developed structure (e.g.

341 Bal 1, Fig. 7) to no holdfast (e.g. Bal 3, Fig. 7). In open culture, morphological differences

342 were also observed between crosses (Fig. 8), but mainly in terms of total length and weight.

$344 \quad 3.5$ Chemical characterization

345 Chemical analyses were performed for all crosses, except Bal 3 that did not survive the 346 culture conditions in open water. Carbohydrates, bioactive molecules and aminoacids 347 exhibited strong variability and significant differences (Table A2) between crosses. These 348 differences were on several occasions striking: alginate yield was over 3 times higher for 349 Bal 14 than Bal 1, and mannitol was 7.7 times higher for Bal 14 than for Bal 1 (Figure 9A). 350 This same situation was observed for two of the 3 bioactive compounds measured (phenols 351 and phloroglucinol), Bal 14 had values more than 4 times higher for both compounds than 352 Bal 9 (Figure 9B). In the case of aminoacids, 7 out of 16 showed significant differences 353 between the crosses (Table A2). Six of the total number of aminoacids showed differences 354 that did not vary significantly, but the other 11 aminoacids showed significant variation and 355 Arginine and Leucine showed variations up to 2.5 times.

357 4. Discussion

Our analysis based on microsatellites markers and morphological data provides 359 clear evidence of spatial structure within the distribution range of $M$. pyrifera along the 
SEP coast, with strong discontinuities in the distribution of both the genetic and the

361 phenotypic diversities. Four major clusters were identified, which coincide with the

362 geographic distribution of the populations (North, Central, South Pacific/Chacao channel,

363 and Interior Sea of Chiloé). the lack of isolation by distance further supports the idea that,

364 at the spatial scales considered in this study (from tens to hundreds of kilometers, and up to

$3652,600 \mathrm{~km}$ in total), the genetic diversity is structured into major clusters representing 366 mainly regional groupings separated by discontinuities in the genetic identity of

367 individuals. Some of these discontinuities are co-located with environmental breaks. For

368 instance, a sharp discontinuity along the Chacao channel, in between the Island of Chiloé

369 and the continent (35 km long and 4-6 km wide) separates the interior sea from the open

370 coast, environments that differ in terms of wave exposure, salinity variation, water

371 stratification and nutrient abundance. A second major discontinuity separates populations

372 south of $33^{\circ} \mathrm{S}$, characterized by strong but intermittent upwelling regimes, from populations

373 north of $30^{\circ} \mathrm{S}$ dominated by weaker but more persistent over time upwelling [58]. These

374 discontinuities correspond to previously described biogeographic boundaries (i.e. $30-33^{\circ} \mathrm{S}$

375 and $\left.40-42^{\circ} \mathrm{S}\right)[57,59]$ and are strongly associated with the phylogeographic discontinuities

376 of a large number of invertebrates (see [60] and references therein) and seaweeds [61],

377 which on occasions leads to speciation [62]. Habitat heterogeneity plays an important role

378 in kelp divergence by favoring adaptation to particular environmental conditions, as shown

379 for the Lessonia species complex $[62,63,64,65]$. Phylogeographic analyses of $M$. pyrifera

380 across the southern hemisphere have also revealed genetic discontinuities associated with

381 these environmental frontiers [41] suggesting that the distribution of genetic diversity is

382 strongly driven by the distribution of different habitats. The northernmost cluster, 383 represented by a single sampled population (Antofagasta), does not appear to be isolated by 
any known environmental discontinuity. Analysis of other seaweed species along the SEP coast have indicated genetic discontinuities that do not coincide with biogeographic boundaries (e.g. Mazzaella laminarioides [66]), but with large interruptions in suitable habitat (e.g. long sandy beaches). Even though there is no such interruption of the rocky shore between Choros and Antofagasta, there is a total absence of $M$. pyrifera along a large section of coastline running approximately $600 \mathrm{~km}$, south of Antofagasta [67]. Such an interrupted distribution might be the cause of the significant differentiation of the Antofagasta population, as gene flow seems to occur over relatively short distances. Indeed, dispersal of this species is dominated by spore dispersal at scales of a few meters, leading to high inbreeding within and strong differentiation among populations [68]. It is possible that the Algarrobo-Choros cluster, located within the $30-33^{\circ} \mathrm{S}$ biogeographic transition between the Peruvian Province and the Intermediate Area [57], is poorly connected to the northern cluster because of both restrictions in dispersal due to the distances between populations and local adaptations caused by habitat divergence.

The strong concordance between morphological and genetic clustering further suggests environmental conditions are driving the evolutionary divergence between regions. Phenotypic plasticity has often been considered as an explanation for the diversity of phenotypic traits found along the coast. The morphological characters of the sporophytes considered here include those that used to be diagnostic for the distinction between $M$. integrifolia and $M$. pyrifera: holdfast shape, blade and aerocysts size. The observations of the integrifolia- morphotype along wave exposed rocky shores, and the pyrifera morphotype in the Interior Sea of Chiloé were considered plastic responses to the exposure to wave action (or the absence of it) [39]. There is, however, evidence of genetic control of some traits, as demonstrated by the differential growth of juveniles of Macrocystis under 
variable nutrient concentrations within common garden experiments [69]. Evidence of a phylogenetic signature of the morphological divergence between pyrifera and integrifolia types suggest that $M$. pyrifera is experiencing an incipient evolutionary divergence between the two morphotypes along southern hemisphere coastlines that can potentially be explained by the different environments that they inhabit [40]. However, gene flow is still occurring between both groups as indicated by laboratory results [70], which are consistent with our results for a few admixed individuals in each cluster. Here, not only did we observe spatial clusters for morphological data, but when combining data sets in a discriminant analysis, the existence of these morphological clusters was well explained by their association with the genetic clusters. In other words, the species seems to be experiencing evolutionary divergence between different habitats. This reinforces the idea that the phenotypic diversity observed in $M$. pyrifera is an evolutionary response to environmental heterogeneity rather than pure phenotypic plasticity. The results of our limited crossing experiments, with as few as 9 male/female combinations, strongly reinforce this hypothesis. First, considerable variation was observed for all the analyzed traits, including shape, size, growth rate and chemical composition. Second, this limited sampling of natural diversity provided, after a single generation, evidence of strongly heritable variation, as each progeny was highly homogeneous in the common garden experiments (both in tanks and out-door), but very different from any other progeny. For instance, the observation of variation in the holdfast morphology, ranging from normal pyrifera type, to reduced structures, to total absence of a holdfast, is experimental proof of the strong genetic determinism of holdfast shape. Parental sporophytes all came from sheltered habitats, where selection for holdfast size may be weak and could allow individuals with small sized holdfasts to survive. Therefore, these populations may have 
432

433

434

435

436

437

438

439

440

441

442

443

444

445

446

447

448

449

450

451

452

453

454

455

retained some genetic variance for holdfast shape. This might not be expected in waveexposed populations where the drag forces eliminate individuals weakly attached to the substratum, and therefore tend to eliminate genetic variance for holdfast shape (i.e. purifying selection). These results may explain the phylogenetic signal of holdfast morphology previously described [40]. Such a hypothesis could be further tested by analyzing the variance of holdfast phenotypes in the progeny of sporophytes living in protected versus wave-exposed habitats. To conclude, holdfast shape may acquire some characteristics from the influence of the environment during early development [39], but the genetic background of the different progeny is the main driver of variability in these common garden experiments. Similar conclusions can be drawn for the chemical composition, which also strongly suggests that sporophyte physiology is under genotypic control [69], although seasonal variation is also known [32].

Heritable variation of phenotypic diversity is one of the fundamental predictions of Darwin's theory of evolution under natural selection. Altogether, our results strongly suggest that the diversity of phenotypic traits is under the strong influence of natural selection. Besides a recent evolutionary history of the species in the southern hemisphere [41], the amount and distribution of this heritable variation is likely the result of evolutionary divergence between the different habitats. Therefore, the usually recognized phenotypic plasticity of the giant kelp, as an explanation of its broad distribution, should be reconsidered and local adaptation should be experimentally tested among habitats.

The introduction of new varieties for seaweed cultivation is posing a number of biological challenges. For example, over reliance on genetically uniform breeds that, often have unstable performance and get discarded from the production lines after only a few 
years [71]. This genetic homogeneity also increases vulnerability to environmental stress

457 and pests, because of intensification [72]. However, these varieties have fixed certain 458 economically important traits, questioning the influence of phenotypic plasticity in 459 Laminariales. Many traits related to economic production and quality are quantitatively 460 inherited, and determined by the combined interaction between genetic and environmental 461 factors. Therefore, understanding the relationship between the genotype and the 462 environment and their role in shaping phenotypes will accelerate our capacity to selectively 463 breed and improve the agronomic performance of cultivated strains. Recent advances in 464 QTL analyses of seaweed traits [73] offer an alternative approach for demonstrating the 465 role of the genetic background, and allow for a move towards the development of tools to 466 assist selective breeding. Additionally, by suggesting that some processes of local 467 adaptation are occurring in giant kelp populations along the SEP coast, our results should 468 be relevant to the development of cultivars that fit into local/regional environments. Indeed, $469 M$. pyrifera as well as most other kelps that are being incipiently cultivated are still wild 470 species that evolved genetic combinations that optimize the fitness of different genotypes in 471 their local environment. Therefore, initial steps of selective breeding should assess 472 unwanted consequences of breaking these optimal combinations and take into consideration 473 the nature of the genetic resources and natural variation available in wild seaweed stocks, in 474 order to achieve sustainable improvement of the agronomic performances of the cultivars in 475 their native environment [18]. In this context, wild-type genetic diversity needs to be tested 476 under farming conditions and preserved and stored in germplasms [30] for subsequent 477 breeding experiments.

478 In the current context of an increasing demand for seaweed biomass not only for 479 hydrocolloids industry, but also for a much larger range of high value molecules for 
different industries, understanding and preserving the natural genetic diversity of the breed-

481 stock is a pre-requisite for developing efficient breeding strategies that will increase

482 production through farming. Genotype and phenotype diversities within wild populations

483 offer a large panel of interesting traits for the industry. We should also take advantage of 484 the evolutionary history of the species, which has promoted genetic combinations 485 optimized for the different habitats a species can occupy naturally. In this context, the high 486 heritable variance for phenotypic diversity revealed by $M$. pyrifera represents a natural 487 heritage, potentially highly valuable to the success of future breeding programs.

488

489 Acknowledgements

$490 \quad$ The authors acknowledge the support of Corfo-INNOVA through their program 09-

491 CTEI-6866 and the Programa Basal from CONICYT (FB-0001). CC and SF also 492 acknowledge the support of FONDECYT (1160930) and SF of Iniciativa Cientifica 493 Milenio (ICM P10-033F).

494

495 Author Contributions

496 C.C., S.F., and A.H.B. planned and designed the research. C.C. carried out the sampling 497 and the laboratory work. C.C. and S.F. performed the analyses. C.C., S.F., and A.H.B. 498 wrote the manuscript.

500 References

$501 \times[1]$ S.L. Holdt, S. Kraan, Bioactive compounds in seaweed: Functional food 
502 applications and legislation, J. Appl. Phycol. 23 (2011) 543-597. doi:10.1007/s10811-010$503 \quad 9632-5$.

504 [2] E. Ibañez, A. Cifuentes, Benefits of using algae as natural sources of functional 505 ingredients, J. Sci. Food Agric. 93 (2012) 703-709. doi:10.1002/jsfa.6023.

506 [3] J.T. Hafting, J.S. Craigie, D.B. Stengel, R.R. Loureiro, A.H. Buschmann, C. Yarish, 507 M.D. Edwards, A.T. Critchley, Prospects and challenges for industrial production of 508 seaweed bioactives, J. Phycol. 51 (2015) 821-837. doi:10.1111/jpy.12326.

509 [4] H.A.R. Suleria, G. Gobe, P. Masci, S.A. Osborne, Marine bioactive compounds and 510 health promoting perspectives; innovation pathways for drug discovery, Trends Food Sci. 511 Technol. 50 (2016) 44-55. doi:10.1016/j.tifs.2016.01.019.

512 [5] M.L. Wells, P. Potin, J.S. Craigie, J.A. Raven, S.S. Merchant, K.E. Helliwell, A.G. 513 Smith, M.E. Camire, S.H. Brawley, Algae as nutritional and functional food sources: 514 revisiting our understanding, J. Appl. Phycol. (2016) 1-34. doi:10.1007/s10811-016-09745155.

516 [6] C. Loureiro, R., Gachon, C.M.M., Rebours, Seaweed cultivation: potential 517 challenges of crop domestication at an unprecedented pace, New Phytol. 206 (2015) 489518492.

519 [7] C. Rebours, E. Marinho-Soriano, J.A. Zertuche-González, L. Hayashi, J.A. 520 Vásquez, P. Kradolfer, G. Soriano, R. Ugarte, M.H. Abreu, I. Bay-Larsen, G. Hovelsrud, R. 521 Rodven, D. Robledo, Seaweeds: An opportunity for wealth and sustainable livelihood for 522 coastal communities, J. Appl. Phycol. 26 (2014) 1939-1951. doi:10.1007/s10811-014$523 \quad 0304-8$

524 [8] FAO, The State of World Fisheries and Aquaculture 2016. Contributing to food 525 security and nutrition for all. Rome. 200pp. 
526 [9] G. Acquaah, Principles of Plant Genetics and Breeding, 2012. 527 doi:10.1017/CBO9781107415324.004.

528 [10] T. Gjedrem, Genetic improvement for the development of efficient global 529 aquaculture: A personal opinion review, Aquaculture. 344-349 (2012) 12-22. 530 doi:10.1016/j.aquaculture.2012.03.003.

531 [11] X. Li, Z. Zhang, S. Qu, G. Liang, J. Sun, N. Zhao, C. Cui, Z. Cao, Y. Li, J. Pan, S. Yu, 532 Q. Wang, X. Li, S. Luo, S. Song, L. Guo, G. Yang, Improving seedless kelp (Saccharina 533 japonica) during its domestication by hybridizing gametophytes and seedling-raising from 534 sporophytes, Sci. Rep. 6:21255 (2016) 1-9. doi:10.1038/srep21255.

535 [12] T.F. Shan, S.J. Pang, S.Q. Gao, Breeding of an elite cultivar Haibao No.1 of Undaria 536 pinnatifida (Phaeophyceae) through gametophyte clone crossing and consecutive selection, 537 J. Appl. Phycol. 28 (2016) 2419-2426. doi:10.1007/s10811-015-0748-5.

538 [13] X.H. Yan, F. Lv, C.J. Liu, Y.F. Zheng, Selection and characterization of a high539 temperature tolerant strain of Porphyra haitanensis Chang et Zheng (Baqngiales, 540 Rhodophyta)., J. Appl. Phycol. 22 (2010) 511-516. doi:10.1007/s10811-009-9486-X.

$541[14]$ N. Robinson, P. Winberg, L. Kirkendale, Genetic improvement of macroalgae: 542 Status to date and needs for the future, J. Appl. Phycol. 25 (2013) 703-716. 543 doi:10.1007/s10811-012-9950-x.

544 [15] I.K. Chung, J.H. Oak, J.A. Lee, J.A. Shin, J.G. Kim, K. Park, adaptation against 545 global warming: Korean Project Overview, $70 \quad$ (2013) 1038-1044. 546 doi:10.1093/icesjms/fss206.

547 [16] C. Peteiro, N. Sánchez, B. Martínez, Mariculture of the Asian kelp Undaria 548 pinnatifida and the native kelp Saccharina latissima along the Atlantic coast of Southern 549 Europe: An overview, Algal Res. 15 (2016) 9-23. doi:10.1016/j.algal.2016.01.012. 
551 of Kappaphycus in the Philippines: more than four decades of farming, J. Appl. Phycol. 27

552 (2015) 1945-1961. doi:10.1007/s10811-014-0510-4.

553 [18] M. Valero, M.-L. Guillemin, C. Destombe, B. Jacquemin, C.M.M. Gachon, Y. 554 Badis, A.H. Buschmann, C. Camus, S. Faugeron, Perspectives on domestication research 555 for sustainable seaweed aquaculture, Perspect. Phycol. (2017) 1-14. 556 doi:10.1127/PIP/2017/0066.

557 [19] S.G. Marshall, D.J., Morgan, Ecological and evolutionary consequences of linked 558 life-history stages in the sea, Curr. Biol. 21 (2011) 718-725.

559 [20] M.L. Guillemin, S. Faugeron, C. Destombe, F. Viard, J.A. Correa, M. Valero, 560 Genetic variation in wild and cultivated populations of the haploid- diploid red alga 561 Gracilaria chilensis: How farming practices favor asexual reproduction and heterozygosity, 562 Evolution (N. Y). 62 (2008) 1500-1519. doi:10.1111/j.1558-5646.2008.00373.x.

563 [21] M.L. Guillemin, P. Valenzuela, J.D. Gaitán-Espitia, C. Destombe, Evidence of 564 reproductive cost in the triphasic life history of the red alga Gracilaria chilensis 565 (Gracilariales, Rhodophyta), J. Appl. Phycol. 26 (2013) 569-575. doi:10.1007/s10811-013$566 \quad 0072-x$.

567 [22] M.L. Guillemin, M. Valero, S. Faugeron, W. Nelson, C. Destombe, Tracing the 568 trans-pacific evolutionary history of a domesticated seaweed (Gracilaria chilensis) with 569 archaeological and genetic data, PLoS One. 9 (2014). doi:10.1371/journal.pone.0114039.

570 [23] A.H. Buschmann, F.A. Kuschel, P.A. Vergara, J. Schulz, Intertidal Gracilaria 571 farming in southern Chile: differences of the algal proveniance, Aquat. Bot. 42 (1992) 327$572 \quad 337$.

573 [24] E.I. Ask, R. V. Azanza, Advances in cultivation technology of commercial 
574 eucheumatoid species: A review with suggestions for future research, Aquaculture. 206 575 (2002) 257-277. doi:10.1016/S0044-8486(01)00724-4.

576 [25] X. Li, G. Yang, Y. Shi, Y. Cong, S. Che, S. Qu, Z. Li, Prediction of the heterosis of 577 Laminaria hybrids with the genetic distance between their parental gametophyte clones, J. 578 Appl. Phycol. 20 (2008) 1097-1102. doi:10.1007/s10811-008-9321-9.

579 [26] X. Li, J. Liu, Y. Cong, S. Qu, Z. Zhang, H. Dai, S. Luo, X. Han, S. Huang, Q. 580 Wang, G. Liang, J. Sun, Y. Jin, D. Wang, G. Yang, Breeding and trial cultivation of 581 Dongfang No. 3, a hybrid of Laminaria gametophyte clones with a more than intraspecific 582 but less than interspecific relationship, Aquaculture. $280 \quad$ (2008) 76-80. 583 doi:10.1016/j.aquaculture.2008.05.005.

584 [27] C. Halling, S.A. Wikström, G. Lilliesköld-Sjöö, E. Mörk, E. Lundsør, G.C. 585 Zuccarello, Introduction of Asian strains and low genetic variation in farmed seaweeds: 586 Indications for new management practices, J. Appl. Phycol. 25 (2013) 89-95. 587 doi:10.1007/s10811-012-9842-0.

588 [28] T.F. Shan, S.J. Pang, J. Li, X. Li, De novo transcriptome analysis of the 589 gametophyte of Undaria pinnatifida (Phaeophyceae), J. Appl. Phycol. 27 (2015) 1011590 1019. doi:10.1007/s10811-014-0393-4.

591 [29] K. Avia, S.M. Coelho, G.J. Montecinos, A. Cormier, F. Lerck, S. Mauger, S. 592 Faugeron, M. Valero, J.M. Cock, P. Boudry, High-density genetic map and identification of 593 QTLs for responses to temperature and salinity stresses in the model brown alga 594 Ectocarpus, Sci. Rep. 7 (2017) 43241. doi:10.1038/srep43241.

595 [30] S. Barrento, C. Camus, I. Sousa-Pinto, A.H. Buschmann, Germplasm banking of the 596 giant kelp: Our biological insurance in a changing environment, Algal Res. 13 (2016) 134597 140. doi:10.1016/j.algal.2015.11.024. 
598 [31] A.H. Buschmann, P. Steven, P. Potin, S. Faugeron, J.A. Vásquez, C. Camus, J. 599 Infante, M.C. Hernández-González, A. Gutiérrez, D.A. Varela, The status of kelp 600 exploitation and marine agronomy, with emphasis on Macrocystis pyrifera, in Chile, in: 601 N.B. JP Jacquot, P Gadal (Ed.), Adv. Bot. Res. Vol 71. Sea Plants, Academic Press, 602 Elsevier Ltd., 2014: pp. 161-188. doi:10.1016/j.jeconom.2008.05.014.

603 [32] C. Camus, J. Infante, A.H. Buschmann, Overview of 3 year precommercial 604 seafarming of Macrocystis pyrifera along the Chilean coast, 2014 (2017) 1-17. 605 doi:10.1111/raq.12185.

606 [33] C. Camus, A.H. Buschmann, Macrocystis pyrifera aquafarming: Production 607 optimization of rope-seeded juvenile sporophytes, Aquaculture. 468 (2017) 107-114. 608 doi:10.1016/j.aquaculture.2016.10.010.

609 [34] A.J. Wargacki, E. Leonard, M.N. Win, D.D. Regitsky, C.N.S. Santos, P.B. Kim, 610 S.R. Cooper, R.M. Raisner, A. Herman, A.B. Sivitz, A. Lakshmanaswamy, Y. Kashiyama, 611 D. Baker, Y. Yoshikuni, An engineered microbial platform for direct biofuel production 612 from brown macroalgae, Science 335 (2012) 308-313. doi:10.1126/science.1214547.

613 [35] C. Camus, P. Ballerino, R. Delgado, A. Olivera-Nappa, C. Leyton, A.H. 614 Buschmann, Scaling up bioethanol production from the farmed brown macroalga 615 Macrocystis pyrifera in Chile, Biofuels, Bioprod. Biorefining. 10 (2016) 673-685. 616 doi:10.1002/bbb.

617 [36] J. Ortiz, E. Uquiche, P. Robert, N. Romero, V. Quitral, C. Llantén, Functional and 618 nutritional value of the Chilean seaweeds Codium fragile, Gracilaria chilensis and 619 Macrocystis pyrifera, Eur. J. Lipid Sci. Technol. 111 (2009) 320-327. 620 doi:10.1002/ejlt.200800140.

621 [37] A. Leyton, R. Pezoa-Conte, A. Barriga, A.H. Buschmann, P. Mäki-Arvela, J.P. 
622 623 624 625 626 627 628 629 630 631 632 633 634 635 636 637 638 639 640 641 642 643 644 645

Mikkola, M.E. Lienqueo, Identification and efficient extraction method of phlorotannins from the brown seaweed Macrocystis pyrifera using an orthogonal experimental design, Algal Res. 16 (2016) 201-208. doi:10.1016/j.algal.2016.03.019.

[38] L. Druehl, Louis D., Kemp, Morphological and growth responses of geographically isolated Macrocystis pyrifera populations when grown in a common environment, Can. J. Bot. 60 (1982) 1409-1413.

[39] K.W. Demes, M.H. Graham, T.S. Suskiewicz, Phenotypic plasticity reconciles incongruous molecular and morphological taxonomies: The giant kelp, Macrocystis (laminariales, phaeophyceae), is a monospecific genus, J. Phycol. 45 (2009) 1266-1269. doi:10.1111/j.1529-8817.2009.00752.x.

[40] M.P. Astorga, C.E. Hernández, C.P. Valenzuela, J. Avaria-Llautureo, R. Westermeier, Origin, diversification, and historical biogeography of the giant kelp genus Macrocystis: Evidences from Bayesian phylogenetic analysis, Rev. Biol. Mar. Oceanogr. 47 (2012) 573-579. doi:10.4067/S0718-19572012000300019.

[41] E.C. Macaya, G.C. Zuccarello, Genetic structure of the giant kelp Macrocystis pyrifera along the southeastern Pacific, Mar. Ecol. Prog. Ser. 420 (2010) 103-112. doi:10.3354/meps08893.

[42] E. Faugeron, S., Veliz, D., Peralta, G., Tapia, J., Tellier, F., Billot, C., Martinez, Development and characterization of nine polymorphic microsatellite markers in the Chilean kelp Lessonia nigrescens., Mol. Ecol. Resour. 9 (2009) 937-939.

[43] F. Alberto, A. Whitmer, N.C. Coelho, M. Zippay, E. Varela-Alvarez, P.T. Raimondi, D.C. Reed, E.A. Serraö, Microsatellite markers for the giant kelp Macrocystis pyrifera, Conserv. Genet. 10 (2009) 1915-1917. doi:10.1007/s10592-009-9853-9.

[44] W. Amos, J.I. Hoffman, A. Frodsham, L. Zhang, S. Best, A.V.S. Hill, Automated 
646 binning of microsatellite alleles: Problems and solutions, Mol. Ecol. Notes. 7 (2007) 10-14. 647 doi:10.1111/j.1471-8286.2006.01560.x.

648 [45] F. Belkhir, Khalid., Borsa P., Chikhi, L., Raufaste, N., Bonhomme, GENETIX 4.05, 649 logiciel sous Windows TM pour la génétique des populations., n.d.

650 [46] J.K. Pritchard, M. Stephens, P. Donnelly, Inference of population structure using 651 multilocus genotype data, Genetics. 155 (2000) 945-959. doi:10.1111/j.1471$652 \quad 8286.2007 .01758 . x$.

653 [47] G. Evanno, S. Regnaut, J. Goudet, Detecting the number of clusters of individuals 654 using the software STRUCTURE: A simulation study, Mol. Ecol. 14 (2005) 2611-2620. 655 doi:10.1111/j.1365-294X.2005.02553.x.

656 [48] K. Lüning, M.J. Dring, Reproduction, growth and photosynthesis of gametophytes of 657 Laminaria saccharina grown in blue and red light, Mar. Biol. 29 (1975) 195-200.

658 [49] R. Westermeier, D. Patiño, M.I. Piel, I. Maier, D.G. Mueller, A new approach to 659 kelp mariculture in Chile: Production of free-floating sporophyte seedlings from 660 gametophyte cultures of Lessonia trabeculata and Macrocystis pyrifera, Aquac. Res. 37 661 (2006) 164-171. doi:10.1111/j.1365-2109.2005.01414.x.

662 [50] I. Jaswir, D. Noviendri, H.M. Salleh, K. Miyashita, Fucoxanthin extractions of 663 brown seaweeds and analysis of their lipid fraction in methanol, Food Sci. Technol. Res. 18 664 (2012) 251-257.

665 [51] R. Koivikko, J. Loponen, K. Pihlaja, V. Jormalainen, High-performance liquid 666 chromatographic analysis of phlorotannins from the brown alga Fucus vesiculosus, 667 Phytochem. Anal. 18 (2007) 326-332. doi:10.1002/pca.986.

668 [52] N. Heffernan, T.J. Smyth, A. Soler-Villa, R.J. Fitzgerald, N.P. Brunton, Phenolic 669 content and antioxidant activity of fractions obtained from selected Irish macroalgae 
670 species (Laminaria digitata, Fucus serratus, Gracilaria gracilis and Codium fragile), J. 671 Appl. Phycol. (2014). doi:10.1007/s10811-014-0291-9.

672 [53] L. Auezova, F. Najjar, O. Selivanova, E. Hajj Moussa, M. Diab Assaf, Antioxidant 673 activity of brown alga Saccharina bongardiana from Kamchatka (Pacific coast of Russia). 674 A methodological approach, J. Appl. Phycol. 25 (2013) 1189-1196. doi:10.1007/s10811675 012-9932-Z.

676 [54] E. Cruces, P. Huovinen, I. Gómez, Phlorotannin and antioxidant responses upon 677 short-term exposure to UV radiation and elevated temperature in three south Pacific kelps, 678 Photochem. Photobiol. 88 (2012) 58-66. doi:10.1111/j.1751-1097.2011.01013.x.

679 [55] D.P. Cohen, S.A., de Antonis, K., Michaud, Compositional protein analysis using 6680 aminoquinolyl-N-hydroxysuccinimidyl carbamate, a novel derivatization reagent., in: Tech. 681 Protein Chem. IV, Academy Press, San Diego, California, 1993: pp. 289-298.

682 [56] D.P. Cohen, S.A., Michaud, Synthesis of a fluoresecent derivatizing reagent, 6683 aminoquinolyl-N-hydroxysuccinimidyl carbamate, and its application for the analysis of 684 hydrolysate amino acids via high performance liquid chromatography., Anal. Biochem. 211 685 (1993) 279-287.

686 [57] P.A. Camus, Biogeografía marina de Chile continental, Rev. Chil. Hist. Nat. 74 687 (2001) 587-617. doi:10.4067/S0716-078X2001000300008.

688 [58] F.J. Tapia, J.L. Largier, M. Castillo, E.A. Wieters, S.A. Navarrete, Latitudinal 689 discontinuity in thermal conditions along the nearshore of Central-Northern Chile, PLoS 690 ONE 9 (2014) e110841. 
692

693

694

695

696

697

698

699

700

701

702

703

704

705

706

707

708

709

710

711

712

713
[59] I. Meneses, B. Santelices, Patterns and breaking points in the distribution of benthic algae along the temperate Pacific coast of South America, Rev. Chil. Hist. Nat. 73 (2000) $615-623$.

[60] P.A. Haye, N.I. Segovia, N.C. Muñoz-Herrera, F.E. Gálvez, A. Martínez, A. Meynard, M.C. Pardo-Gandarillas, E. Poulin, S. Faugeron, Phylogeographic structure in benthic marine invertebrates of the Southeastern Pacific Coast of Chile with differing dispersal potential, PLoS ONE (2014) e88613.

[61] M.L. Guillemin, M. Valero, F. Tellier, E.C. Macaya, C. Destombe, S. Faugeron, Phylogeography of seaweeds in the South East Pacific: Complex evolutionary processes along a latitudinal gradient, in: Z.M. Hu, C. Fraser (Eds.), Seaweed Phylogeography, Springer Science + Business Media Dordrecht, 2016, pp. 251-277.

[62] F. Tellier, A.P. Meynard, J.A. Correa, S. Faugeron, M. Valero, Phylogeographic analyses of the $30^{\circ} \mathrm{S}$ south-east Pacific biogeograqphic transition zone establish the occurrence of a sharp genetic discontinuity in the kelp Lessonia nigrescens: Vicariance or parapatry?, Mol. Phylogenet. Evol. 53 (2009) 679-693. doi: 10.1016/j.ympev.2009.07.030.

[63] V.L. Oppliger, J.A. Correa, S. Faugeron, J. Beltrán, F. Tellier, M. Valero, C. Destombe, Sex ratio variation in the Lessonia nigrescens complex (Laminariales, Phaeophyceae): effect of latitude, temperature and marginality, J. Phycol. 47 (2011) 5-12. doi: 10.111/j. 1529-8817.2010.00930.x.

[64] C. López-Cristoffanini, F. Tellier, R. Otaíza, J.A. Correa, L. Contreras-Porcia, Tolerance to air exposure: a feature driving the latitudinal distribution of two sibling kelp species, Bot. Mar. 56 (2013) 431-440. 
714 [65] K. Koch, M. Thiel, F. Tellier, W. Hagen, M. grave, F. Tala, P. Laeseke, K. Bischof, 715 Species separation within the Lessonia nigrescens complex (Phaeophyceae, Laminariales) 716 is mirrored by ecophysiological traits. Bot. Mar. 58 (2015) 81-92.

717 [66] A. Montecinos, B.R. Broitman, S. Faugeron, P.A. Haye, F. Tellier, M.L. Guillemin, 718 Species replacement along a linear coastal habitat: phylogeography and speciation in the 719 red alga Mazzaella laminarioides along the South East Pacific, BMC Evol. Biol. 12 (2012) 720 97. doi: 10.1186/1471-2148-12-97

721 [67] J.A. Vásquez, Evaluación de la biomasa de praderas naturales y prospección de 722 potenciales lugares de repoblamiento de algas pardas en la costa de las XV, I y II regiones. 723 Reporte Final FIP 2008-39 (2010) Available at: www.subpesca.cl/fipa/613/articles724 89246_informe_final.pdf.

725 [68] M.L. Johansson, P.T. Raimondi, D.C. Reed, N.C. Coelho, E.A. Serräo, F.A. Alberto, 726 Looking into the black box: simulating the role of self-fertilization and mortality in the 727 genetic structure of Macrocystis pyrifera, Mol. Ecol. 22 (2013) 4842-4854. doi: $728 \quad 10.111 / \mathrm{mec} .12444$.

729 [69] C.D. Kopczak, R.C. Zimmerman, J.N. Kremer, Variation in nitrogen physiology and 730 growth among geographically isolated populations of the giant kelp, Macrocystis pyrifera 731 (Phaeophyta). J. Phycol. 27 (1991) 149-158.

732 [70] R. Westermeier, D. Patiño, D.G. Müller, Sexual compatibility and hybrid formation 733 between the giant kelp species Macrocystis pyrifera and $M$. integrifolia (Laminariales, 734 Phaeophyceae) in Chile. J. Appl. Phycol. 19 (2007) 215-221. doi: 10.1007/s10811-006$735 \quad 9126-7$. 
736 [71] J. Zhang, X. Wang, J.T. Yao, Q. Li, F. Liu, N. Yotsukura, T.N. Krupnova, D. Duan, 737 Effect of domestication in the genetic diversity and structure of Saccharina japonica 738 populations in China, Sci. Rep. 7 (2016) 42158. doi: 10.1038/srep42158.

739 [72] W. T. L. Yong, G. J.W.L. Chin, K.F. Rodrigues, Genetic identification and mass 740 propagation of economically important seaweeds, in: N. Thajuddin, D. Dhanasekaran 741 (Eds.), Algae, Organisms for Inminent Biotechnology, InTech, 2016, pp. 277-305, 742 doi:10.5772/62802.

743 [73] J. Zhang, J.T. Yao, Z.M. Sun, G. Fu, D.A. Galanin, C. Nagasato, T. Motomura, Z.M. $744 \mathrm{Hu}$, D.L. Duan, Phylogeographic data revealed shallow genetic structure in the kelp 745 Saccharina japonica (Laminariales, Phaeophyta), BMC Evol. Biol. 15 (2015) 237. doi: $746 \quad 10.1186 / \mathrm{s} 12862-015-0517-8$. 